
BOVINOS OBJETIVANDO SEU REUSO

\title{
CHARACTERIZATION OF WASTEWATER OF CATTLE SLAUGHTERHOUSE FOR ITS REUSE
}

\author{
DIAS, Isabel Cristina Lopes ${ }^{1 *}$; NUNES, Gilvanda²; CASTRO, Antonio Carlos Leal $\mathrm{de}^{3}$ \\ 1,2 Universidade Federal do Maranhão, Centro de Ciências Exatas e Tecnologia, Departamento de Tecnologia \\ Química - DETEC, CCET-UFMA - Av. Portugueses, 1966 - Bacanga, São Luís - MA, Brasil
}

(fone: +559832728255 )

${ }^{3}$ Universidade Federal do Maranhão, Centro de Ciências Biológicas e da Saúde, Departamento de

Oceanografia e Limnologia, DEOLI-UFMA

(fone: +55 9832728566 )

${ }^{*}$ Autor correspondente

e-mail: ilopesdias@gmail.com

Received 13 June 2016; received in revised form 07 July 2016; accepted 10 July 2016

\section{RESUMO}

Com o maior rebanho bovino comercial do mundo, a geração de efluentes líquidos no Brasil tem crescido enormemente e o não tratamento desses resíduos afeta diretamente os corpos hídricos e solo próximos aos abatedouros. Em face à possibilidade de reutilização de águas residuárias, esta pesquisa analisou a qualidade dos efluentes líquidos gerados durante o abate de bovinos, no município de São Luís, Maranhão, Brasil, avaliando o atendimento da legislação em vigor quanto ao lançamento de efluentes, bem como quanto à possibilidade de reúso. Assim, foram feitas quatro coletas bimestrais de amostras de efluente final obtido na saída da última lagoa da estação de tratamento de efluentes de um dos abatedouros da cidade, para avaliação da sua qualidade físico-química e microbiológica. A caracterização do efluente gerado evidenciou que o mesmo não atendia aos padrões exigidos pela legislação federal vigente, não sendo, portanto, recomendado para o reúso. Alternativas de melhorias foram sugeridas, sendo que estas podem ser adotadas pelos demais abatedouros locais. Assim, este estudo representou uma contribuição ao setor de abatedouros, visando fortalecer a o sistema de fiscalização do Estado e ampliar a discussão relacionada à ausência de políticas públicas, em especial de legislações estaduais pertinentes a esse ramo agroindustrial.

Palavras-chave: matadouro, efluente, reúso.

\section{ABSTRACT}

Brazil has the largest commercial cattle herd in the world, consequently the generation of wastewaters in this country has enormously grown, and the absence of treatment of these residues directly affects water bodies and soil near slaughterhouses. Given the possibility of reusing wastewaters, this study aimed to examine the quality of wastewaters generated during the slaughter of cattle, in São Luís, State Capital of Maranhão, Brazil, evaluating the compliance of the current legislation regarding the discharge of wastewater and the possibility of reusing it. Thus, we carried out four bimonthly sample collections from the final effluent, obtained at the outlet of the last pond of the effluent treatment station of one of the slaughterhouses of São Luís, to evaluate its physicochemical and microbiological quality. The effluent evaluation showed that it did not meet the standards required by the current federal legislation; therefore, it is not recommended to be reused. Some improvement alternatives were suggested, which may be adopted by other local abattoirs. This study represented a contribution to the slaughterhouse sectors, aiming the strengthening of the state inspection system and expansion of discussions related to the absence of public policies, especially regarding state laws relevant to this agribusiness sector.

Keywords: slaughterhouse, effluent, reuse. 


\section{INTRODUÇÃO}

Com o maior rebanho bovino comercial do mundo, o Brasil abateu, somente no ano de 2014, 33.906 milhões de bovinos (IBGE, 2014). Essa volumosa produção se traduz no surgimento de um número crescente de abatedouros no país, sendo um segmento de grande importância na economia brasileira, o qual, segundo Henzel e Silveira (2009), tem se desenvolvido em quase todos os municípios brasileiros.

O incremento na produção nacional das indústrias do setor de carne acarreta em preocupações relativas à conservação ambiental, uma vez que os principais impactos adversos estão relacionados com a geração de efluentes que constituem, pela sua composição, fontes de poluição e contaminação, ameaçando constantemente o ambiente e, em particular, os corpos receptores, tais como o solo e as águas subterrânea e superficial (Dias, 1999; Ferreira et al., 2002). A quantidade e a complexidade das águas residuárias lançadas nos mananciais de água doce desencadeiam sérios problemas ecológicos e episódios com graves consequências para a saúde do ser humano (Nieto, 2000). Vários autores (Del Pozo et al., 2000; Manios et al., 2003; Salminen et al., 2001; Salminen; Rintala 2002) são unânimes em afirmar que as águas residuárias de abatedouros provêm de diferentes etapas dos processos de abate, tais como lavagem dos animais, sangria, esfola, limpeza das carcaças dos animais e limpeza das salas de abate. Segundo estes autores, tais efluentes contêm sangue, partículas de pele e carne, excremento, gorduras, pêlos, frações misturadas de ossos picados, limalhas, farinha de osso e vísceras.

Cordi (2008) explica que atualmente existe um grande interesse, tanto de ordem econômica quanto ambiental e social em que os despejos domésticos e industriais sejam submetidos a tratamentos adequados antes da sua disposição em corpos aquáticos. Giordano (2004) menciona que os sistemas de tratamentos de efluentes têm por objetivo fundamental atender à legislação ambiental e em alguns casos ao reúso de águas. O principal objetivo dos sistemas de tratamento no setor de abate de animais é assegurar o tratamento adequado do efluente de modo que este, ao ser lançado no ambiente, não provoque danos de ordem sanitária, estética ou ecológica (Ghandi, 2005). Deste modo, a evolução dos sistemas de tratamento de efluentes agroindustriais tem disponibilizado tecnologias eficientes para a remoção da carga orgânica (Naime \& Garcia, 2005). Segundo Sousa et al. (2006), a utilização de lagoas de estabilização figura entre os melhores métodos de tratamento de efluentes, principalmente quando esse efluente possui o objetivo de ser reutilizado. Santos (2006), todavia, alerta sobre o gerenciamento de efluentes líquidos no setor de abatedouros, que apresenta sérias dificuldades no atendimento às questões legais na esfera ambiental, de tal modo que os efluentes finais geralmente não têm qualidade suficiente para atender os padrões e a qualidade preconizados na legislação ambiental brasileira. Assim, é preciso caracterizar os efluentes para evitar danos ambientais, demandas legais e prejuízos para a imagem da indústria junto à sociedade.

A presente pesquisa foi desenvolvida em um abatedouro de bovinos localizado no município de São Luís, Estado do Maranhão, com o objetivo de analisar a qualidade físicoquímica e microbiológica do efluente gerado no processo de abate, bem como avaliar o atendimento da legislação em vigor quanto ao lançamento de efluentes, analisando ainda a possibilidade de sua reutilização.

\section{MATERIAL E MÉTODOS}

O abatedouro está localizado no Km 10 da BR-135, entrada do povoado Rio Grande

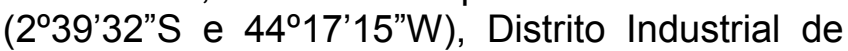
São Luís, Estado do Maranhão (Figura 1).

O efluente final foi coletado em duplicata na saída da última lagoa da estação de tratamento de efluentes - ETE do abatedouro, para análise em triplicata dos parâmetros temperatura $(T)$, potencial hidrogeniônico $(\mathrm{pH})$, óleos e graxas (OG), sólidos em suspensão totais (SST), materiais sedimentáveis (MSD), nitrogênio amoniacal total (NAT), fósforo total (FT), demanda química de oxigênio (DQO), demanda bioquímica de oxigênio (DBO5), coliformes termotolerantes (CT) e Escherichia coli (E. coli). Foram realizadas quatro coletas bimestrais, sendo duas em período seco (setembro e novembro) e duas em período chuvoso (janeiro e março). As amostras de efluente final foram coletadas, preservadas, 
acondicionadas e analisadas de acordo com Standard Methods for the Examination of Water and Wastewater (APHA, 2005) Tabela 1.
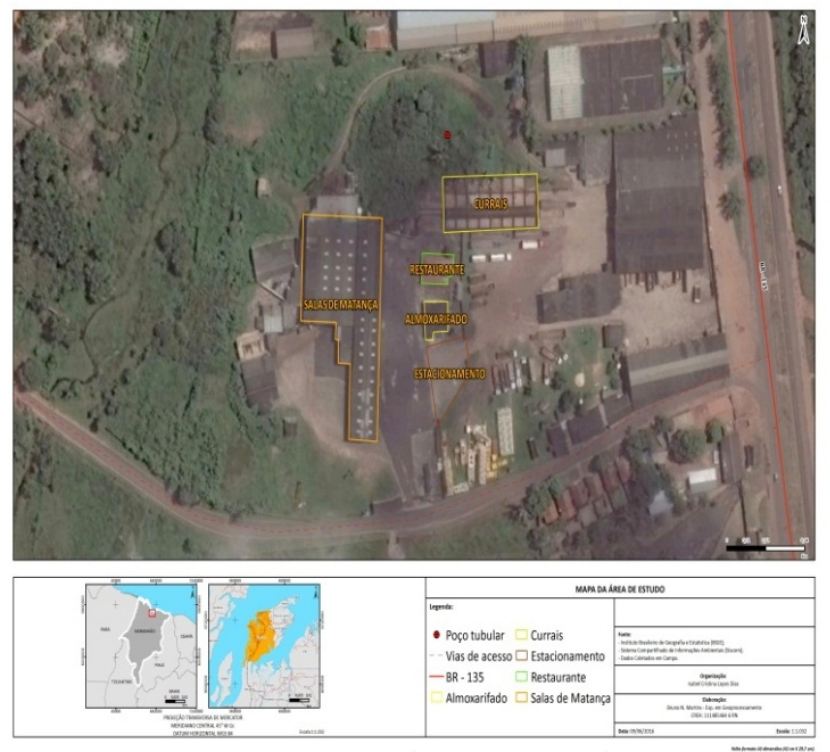

Figura 1. Localização do abatedouro

Tabela 1. Metodologias analíticas e respectivos limites de quantificação dos diferentes parâmetros determinados neste trabalho

\begin{tabular}{lccc} 
Parâm & Unidade & Método & LQ \\
\hline $\mathrm{T}$ & ${ }^{\circ} \mathrm{C}$ & $\mathrm{SM}-2550 \mathrm{~B}$ & -- \\
$\mathrm{pH}$ & - & $\mathrm{SM}-4500 \mathrm{H}_{+} \mathrm{B}$ & $1-13$ \\
$\mathrm{NAT}$ & $\mathrm{mg} / \mathrm{L}$ & $\mathrm{SM}-4500-\mathrm{NH}_{3} \mathrm{~B}, \mathrm{D}$ & -- \\
$\mathrm{FT}$ & $\mathrm{mg} / \mathrm{L}$ & $\mathrm{SM}-4500 \mathrm{P} / \mathrm{B}, \mathrm{E}$ & 0,001 \\
$\mathrm{DQO}$ & $\mathrm{mg} / \mathrm{L}$ & $\mathrm{SM}-5220 \mathrm{D}$ & 17 \\
$\mathrm{DBO}_{5}$ & $\mathrm{mg} / \mathrm{L}$ & $\mathrm{SM}-5210 \mathrm{~B}$ & 1,0 \\
$\mathrm{SST}$ & $\mathrm{mg} / \mathrm{L}$ & $\mathrm{SM}-2540 \mathrm{D}$ & 9,2 \\
$\mathrm{MSD}$ & $\mathrm{mL} / \mathrm{L} / \mathrm{h}$ & $\mathrm{SM}-2540 \mathrm{~F}$ & 0,1 \\
$\mathrm{OG}$ & $\mathrm{mg} / \mathrm{L}$ & $\mathrm{SM}-5520 \mathrm{~B}$ & 4 \\
$\mathrm{CT}$ & $\mathrm{NMP} / 100 \mathrm{~mL}$ & $\mathrm{SM}-9222 \mathrm{D}$ & 1 \\
E. coli & $\mathrm{NMP} / 100 \mathrm{~mL}$ & $\mathrm{SM}-9222 \mathrm{D}$ & 1 \\
\hline
\end{tabular}

Parâm.= Parâmetro; LQ= Limite de quantificação

Os resultados das análises foram comparados aos padrões de lançamento determinados pela legislação brasileira (Brasil, 2011). Os dados foram avaliados a partir de técnicas básicas de análise exploratória e apresentados sob a forma de gráficos. Após a caracterização do efluente, o mesmo foi avaliado de acordo com os padrões de qualidade estipulados para os diferentes usos a que forem destinados.

\section{RESULTADOS E DISCUSSÃO}

O abatedouro está em funcionamento desde o ano de 1993, porém, apenas em 1996 foi inscrito no Serviço de Inspeção Municipal (SIM). Possui uma produção mensal aproximada de três mil bovinos abatidos, com média de 120 cabeças/dia. O responsável técnico é um Médico Veterinário que cuida de vários aspectos dentro da unidade, como gerenciamento administrativo, produtivo e ambiental. A população trabalhadora consiste de 50 funcionários, todos com turno fixo e jornada diária de 6 horas (Tabela 2).

Tabela 2. Identificação do quantitativo de trabalhadores do abatedouro de bovinos avaliado

\begin{tabular}{cc}
\hline Área & Quantitativo \\
\hline Administrativa & 2 \\
Produção & 39 \\
Manutenção & 1 \\
Serviços gerais & 2 \\
Outras & 6 \\
Total & 50 \\
\hline
\end{tabular}

A fonte de abastecimento de água é um poço tubular profundo localizado dentro dos limites do empreendimento $\left(2^{\circ} 39^{\prime} 26 " S\right.$ e $\left.44^{\circ} 17^{\prime} 12^{\prime \prime} \mathrm{W}\right)$, com profundidade de $52 \mathrm{~m}$, de onde são utilizados em torno de $66 \mathrm{~m} 3 / \mathrm{dia}$.

Quanto ao tratamento dos efluentes líquidos, os despejos, provenientes de todas as linhas da sala de matança, são coletados por canaletas e encaminhados para uma linha única que recebe todas as linhas da indústria após o gradeamento para retenção de sólidos grosseiros e gorduras. O efluente gerado, em média 15 $\mathrm{m}^{3} /$ dia, é transportado por meio de caminhãopipa à ETE, localizada a, aproximadamente, 3 $\mathrm{Km}$ do abatedouro (Figura 2).

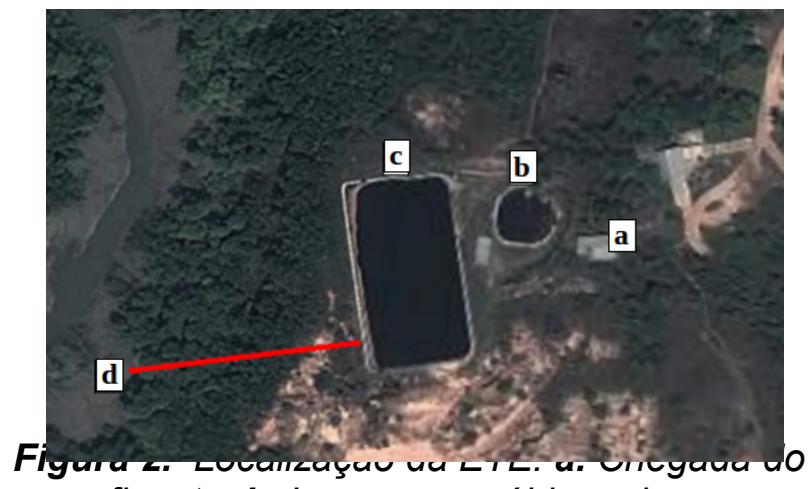

efluente; b. Lagoa anaeróbia; c. lagoa facultativa; $\boldsymbol{d}$. Ponto de lançamento. (Fonte:

PERIÓDICO TCHÊ QUÍMICA • www.periodico.tchequimica.com • Vol. 13 N. 26 • ISSN 1806-0374 (impresso) • ISSN 1806-9827 (CD-ROM) • ISSN 2179-0302 (meio eletrônico) 
Tabela 3. Características das lagoas de

O conjunto utilizado para tratar os efluentes (Figura 3) consistiu no sistema de lagoas de estabilização. $O$ tratamento preliminar é feito pelo de gradeamento (realizado antes do transporte do efluente), seguido do peneiramento fino, que separa as partículas em suspensão com diâmetro acima de $10 \mathrm{~mm}$, realizado logo que $o$ efluente chega à ETE. Após o peneiramento, o efluente cai na caixa de recepção e equalização, que reúne todos os despejos.
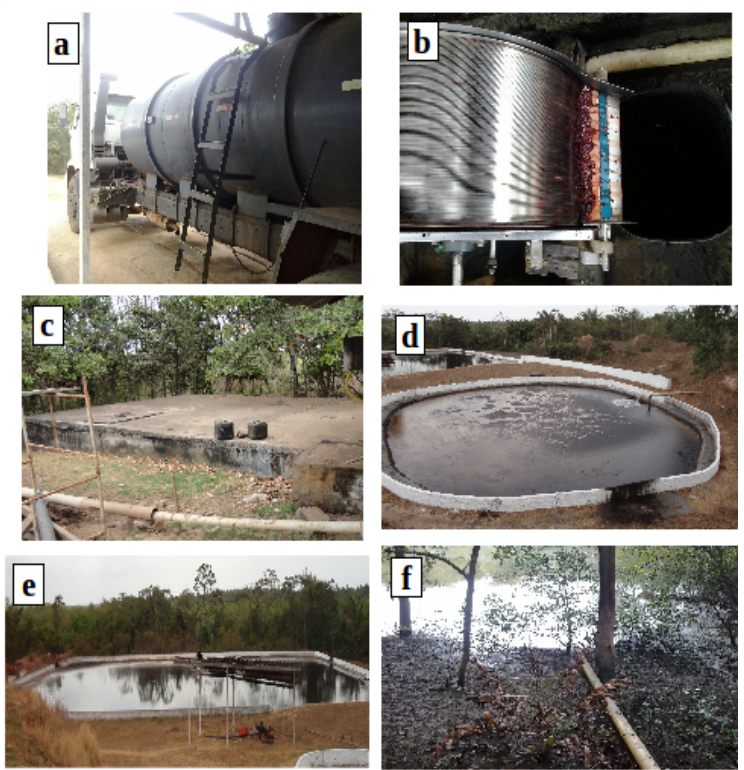

Figura 3. Caracterização da ETE do abatedouro. a. Caminhão utilizado para transportar o efluente; b. Peneiramento fino; c. Caixa de equalização; d. Lagoa anaeróbia; e. Lagoa facultativa; f. Lançamento dos efluentes.

O sistema de lagoas de estabilização consiste de uma lagoa anaeróbia, seguida de uma lagoa facultativa (Tabela 3). Após o tratamento, o efluente é lançado em um manancial superficial (Figura 3f).

\begin{tabular}{ccccc} 
Lagoa de & \multicolumn{5}{c}{ CARACTERÍSTICAS } \\
Estabilização & $\mathrm{A}$ & $\mathrm{P}(\mathrm{m})$ & $\mathrm{V}$ & $\mathrm{TD}$ \\
& $\left(\mathrm{m}^{2}\right)$ & & $\left(\mathrm{m}^{3}\right)$ & $\mathrm{T}$ \\
\hline Anaeróbia & 85,7 & 3,5 & 300 & 5 dias \\
& 2 & & 437, & 7 dias \\
Facultativa & 291, & 1,5 & 5 & 67 \\
\hline
\end{tabular}

$\mathrm{A}=$ área; $\mathrm{P}=$ profundidade; $\mathrm{V}=$ volume; $\mathrm{TD}=$ tempo de detenção.

Segundo Von Sperling (1996), os principais parâmetros de projeto das lagoas facultativas são: tempo de detenção hidráulico, taxa de aplicação superficial e profundidade. Sendo assim, as características visualizadas na Tabela 3 respeitam os parâmetros básicos de dimensionamento adotados por Von Sperling (1996) e Piveli (2003).

$\mathrm{Na}$ Tabela 4 são apresentados os resultados dos parâmetros analisados, destacando-se aqueles que apresentaram limites superiores aos estabelecidos para lançamento de efluentes líquidos, conforme Resolução CONAMA n 430/2011.

Tabela 4. Parâmetros obtidos durante monitoramento dos efluentes gerados no abatedouro

\begin{tabular}{lccccc}
\hline Parâm & SET & NOV & JAN & MAR & $\begin{array}{c}\mathbf{4 3 0 / 1 1} \\
{ }^{*}\end{array}$ \\
\hline T & 25 & 26 & 26,4 & 28,6 & $<40$ \\
pH & 7,5 & 6,9 & 6,8 & 6,4 & 5 a 9 \\
OG & 5 & 5,8 & 8 & 12 & Até 50 \\
SST & 92 & 32 & 400 & 420 & -- \\
MSD & 0,2 & 0,2 & $\mathbf{8}$ & $\mathbf{8}$ & 1 \\
NAT & 12,4 & 137,7 & $\mathbf{4 3 , 5}$ & $\mathbf{5 0 , 4}$ & 20 \\
FT & 11 & 13 & 17 & 21,6 & -- \\
DQO & 205,2 & 510,6 & 1396 & 1810 & -- \\
DBO ${ }_{5}$ & 136 & 460 & 310 & 460 & $60 \%{ }^{* *}$ \\
CT & 640 & 2000 & 950 & 730 & -- \\
E. coli & 230 & 1450 & 480 & 530 & -- \\
\hline \multicolumn{5}{c}{ Parâm.= Parâmetro; LQ= Limite de quantificação } \\
Parâm= Parâmetro; SET=setembro; NOV=novembro; \\
JAN=janeiro; MAR=março. \\
* Resolução Conama n 430/2011. \\
** 60\% de remoção mínima.
\end{tabular}

As médias obtidas para temperatura apresentaram padrão esperado, pois, de acordo

PERIÓDICO TCHÊ QUÍMICA • www.periodico.tchequimica.com • Vol. 13 N. 26

- ISSN 1806-0374 (impresso) • ISSN 1806-9827 (CD-ROM) • ISSN 2179-0302 (meio eletrônico)

(C) 2016. Porto Alegre, RS. Brasil 
com Massé \& Masse (2001) a temperatura das águas residuárias de abatedouros varia, geralmente, entre 20 e $35^{\circ} \mathrm{C}$. Johns (1995) afirma que a temperatura dos efluentes dos sistemas de tratamento dos abatedouros varia significativamente por todo o mundo. Na Europa é frequentemente baixa, em contraste com os efluentes da Austrália, por exemplo, cujos valores variam entre 30 e $35^{\circ} \mathrm{C}$. Em áreas subtropicais estas temperaturas podem subir, o que a princípio, pode ser vantajoso, pois, os sistemas biológicos típicos de tratamento de resíduos são mais eficientes em temperaturas em torno de $37^{\circ} \mathrm{C}$. Observa-se na Figura 4 que as temperaturas do efluente líquido obtidas na presente pesquisa estão abaixo dos limites estipulados pela legislação brasileira (Brasil, 2011).

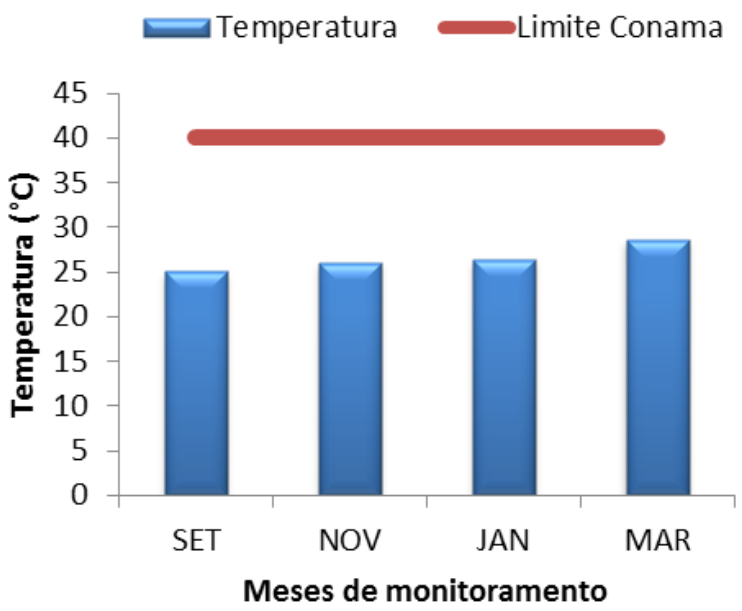

Figura 4. Valores médios de temperatura no efluente líquido do abatedouro de bovinos.

Gil (2010), caracterizando o efluente de ETE de abatedouro em Passo Fundo, RS, encontrou situação semelhante para o parâmetro temperatura. O mesmo observou Barros (2005), ao analisar águas residuárias de abatedouros no Estado de São Paulo, já que as temperaturas médias dos efluentes encontraram-se abaixo dos valores máximos estipulados pela legislação. Torkian et al. (2003), estudando a eficiência de sistemas de tratamento para águas residuárias de abatedouros no Irã, também identificaram efluentes de sistemas de tratamento com temperaturas semelhantes às obtidas neste estudo.

A temperatura é uma das variáveis mais importantes em processos biológicos, porque dela dependem as taxas com que se desenvolvem as reações bioquímicas que determinam a velocidade de crescimento dos micro-organismos e de utilização de substratos (Gomes, 2010). De acordo com Maciel Jr. (2000), aumentos de temperatura resultam na redução de oxigênio dissolvido e no consumo de oxigênio. Além disso, a temperatura é fator determinante na velocidade de uma série de reações que afetam os processos químicos, físicos e biológicos do meio aquático (Gleber, 2002).

Em se tratando da legislação vigente, o $\mathrm{pH}$ obtido neste monitoramento apresentou conformidade com nossa legislação, que recomenda valores entre 5 a 9 (Figura 5). Os valores estiveram sempre próximos de 7, indicando neutralidade. Resultados para este parâmetro foram similares àqueles obtidos em estudos realizados por autores como Caixeta et al. 2002; Torkian et al., 2003 e Barros, 2005.

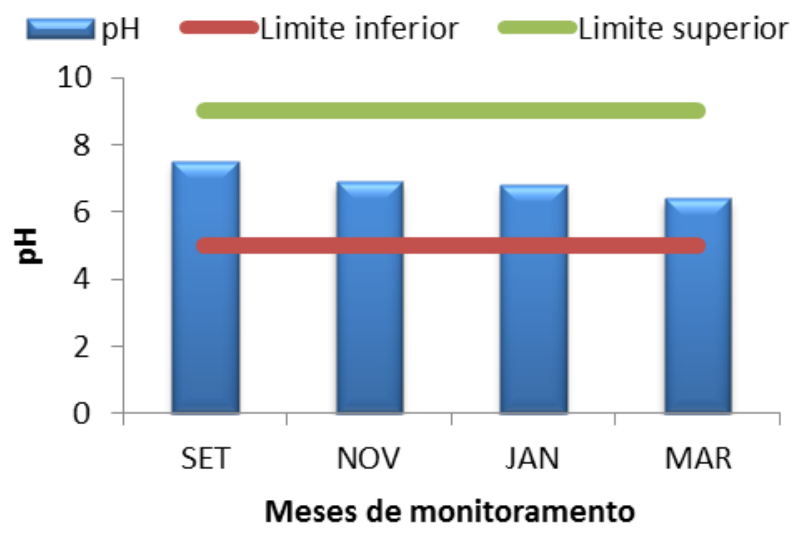

Figura 5. Valores médios de $\mathrm{pH}$ no efluente líquido do abatedouro de bovinos.

Segundo Libânio (2005), o pH influi no grau de solubilidade de várias substâncias, na distribuição das formas livre e ionizada de diversos compostos químicos, como também define o potencial de toxicidade de alguns elementos. Por exemplo, valores de $\mathrm{pH}$ muito básicos (acima de 8,0) tendem a solubilizar a amônia tóxica (NH3), metais pesados e outros sais na água, tornando-os mais biodisponíveis, e precipitar sais de carbonato. Valores de $\mathrm{pH}$ muito ácidos (abaixo de 6,0) tendem a aumentar a concentração de dióxido de carbono (CO2) e ácido carbônico $(\mathrm{H} 2 \mathrm{CO} 3)$ na água (Crepalli, 2007).

Quanto ao teor de óleos e graxas, apesar da variação observada, os resultados encontram- 
se dentro de uma faixa aceitável, já que a atual legislação brasileira estabelece o limite de 50 $\mathrm{mg} / \mathrm{L}$ para óleos vegetais e gorduras animais. Os resultados encontrados nesse trabalho foram bem inferiores aos encontrados por Dornelles (2009), ao avaliar o tratamento dos efluentes gerados em abatedouros do RS (média $72 \mathrm{mg} / \mathrm{L}$ ). Fabbi et al. (2007) e Gil (2010) também obtiveram valores superiores, por ocasião do monitoramento de efluentes em abatedouros, com médias $14,4 \mathrm{mg} / \mathrm{L}$ e $13,5 \mathrm{mg} / \mathrm{L}$, respectivamente; contudo, esses resultados não excederam o limite máximo permitido para este parâmetro. A ocorrência de óleos e gorduras em elevadas concentrações nesse tipo de efluente decorre da grande quantidade de gordura animal oriunda do processo produtivo.

Com relação aos sólidos em suspensão totais (SST), maiores variações foram observadas nos meses de janeiro e março, com nítido aumento entre o período seco e chuvoso. A literatura enumera fatores como temperatura, pressão, pluviosidade, compostos tóxicos, dentre outros, como agentes causadores dessa variabilidade nas características dos esgotos que chegam às estações para tratamento, interferindo grandemente no desempenho de uma ETE (Silva et al., 2005). Vale mencionar que o transporte do efluente aqui pesquisado não sofre influência da pluviosidade; portanto, não foi possível estabelecer uma relação entre este fator ambiental e as variações observadas. Acreditase que a alta concentração seja em decorrência de sua constituição por material de origem orgânica proveniente do próprio processo produtivo e da natureza da matéria prima. Uma vez que não existe limite máximo recomendado pela atual legislação ambiental em relação ao parâmetro SST nesse tipo de efluente, não foi possível afirmar se este se encontra ou não alterado; entretanto, podem-se considerar outros limites de comparação. A Comunidade Europeia, por exemplo, considera para esta variável o limite de $150 \mathrm{mg} / \mathrm{L}$ em efluentes. A Resolução $\mathrm{n}^{\circ}$ 128/2006 do Estado do Rio Grande do Sul preconiza o limite de $180 \mathrm{mg} / \mathrm{L}$ de SST em efluentes líquidos a serem lançados em corpos receptores. De acordo esses dois critérios, o efluente aqui analisado esteve em desacordo nos dois últimos meses de monitoramento.

A análise de materiais sedimentáveis em águas é uma das exigências da legislação ambiental para lançamento de efluentes em corpos d'água, de modo que constantes extrapolações do limite para este parâmetro podem ocasionar prejuízos ambientais, como a elevação do nível de sedimento nas águas dos rios, poluição estética (turvação das águas), perturbação à vida da fauna etc. Os valores médios encontrados no presente estudo mantiveram-se estáveis durante os meses de setembro e novembro; contudo, nos meses de janeiro e março o valor obtido foi de $8 \mathrm{~mL} / \mathrm{L}$, ultrapassando em muito o limite estabelecido pela legislação ambiental, que é $1 \mathrm{~mL} / \mathrm{L}$ (Figura 6).

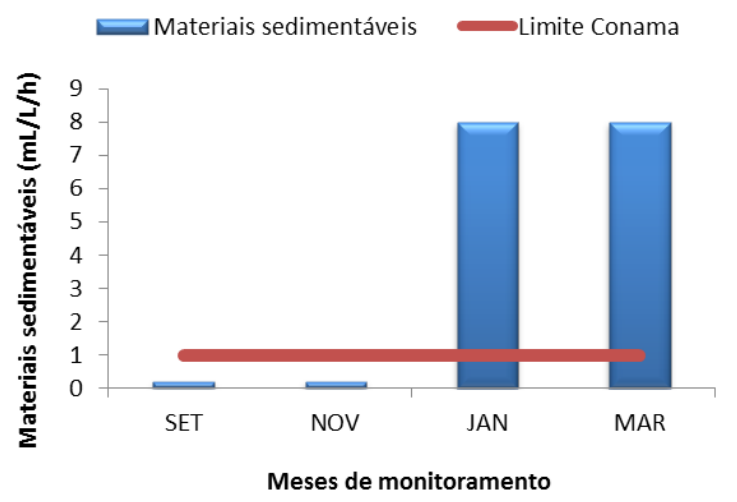

Figura 6. Valores médios de materiais sedimentáveis no efluente do abatedouro.

O processo produtivo de abate, no estabelecimento investigado, ocorre de forma sazonal, gerando quantidades diferentes de efluente a cada dia de trabalho. Isso teve influência direta na variação dos parâmetros, identificada no decorrer do monitoramento, resultando em uma certa dificuldade em se estabelecer um padrão na geração de material sedimentável. Há necessidade, portanto, de se identificar possíveis falhas operacionais, como por exemplo, a falta de uma rotina estabelecida na ETE.

Os resultados detectados no efluente do abatedouro para o nitrogênio amoniacal total mostraram-se em desacordo com a legislação nos três últimos meses de monitoramento (Figura 7). Já o fósforo total, para o qual não existem limites preconizados na legislação brasileira, apresentou valores médios com pouquíssima variação no período do monitoramento. 


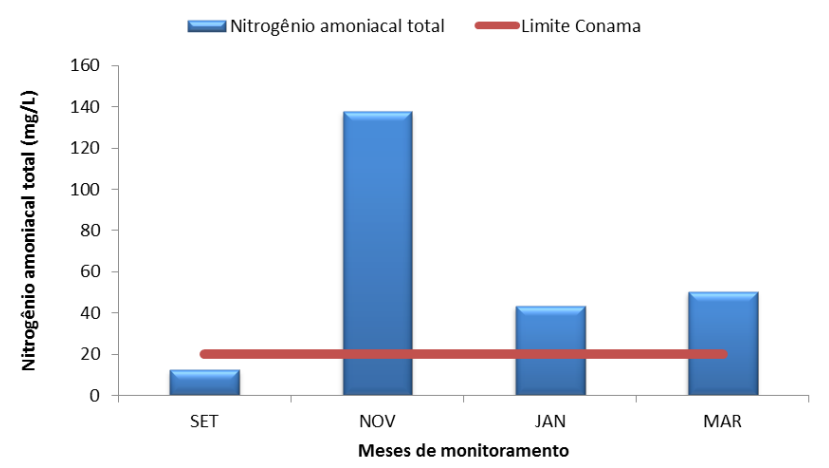

Figura 7. Valores médios de nitrogênio amoniacal total no efluente líquido do abatedouro.

Em alguns estados do país como, por exemplo, no RS, o limite máximo para $P$ total é de $4 \mathrm{mg} / \mathrm{L}$. Com base nesta comparação, verificase que foram elevados os valores obtidos neste monitoramento, indicando a possibilidade de falhas no sistema de tratamento em reduzir este composto e a necessidade de melhorias na qualidade dos efluentes a serem lançados. Considerando as concentrações de nitrogênio e fósforo encontradas, é possível se depreender que os efluentes do estabelecimento em questão possuem forte potencial poluidor, o que vai ao encontro das assertivas de Salminen \& Rintala (2002) e Manios et al. (2003), os quais afirmam que resíduos de abatedouros são geralmente definidos como um difícil substrato a ser tratado, principalmente por causa de seu típico e elevado conteúdo de proteínas e lipídios. Vale ressaltar que esses nutrientes são requeridos na maioria dos processos biológicos, têm grande contribuição para a eutrofização e floração de cianobactérias de ambientes aquáticos, sendo que em tais florações podem estar presentes espécies produtoras de toxinas fatais aos seres vivos (cianotoxinas), inclusive aos humanos (Figueiredo et al., 2007).

Com relação ao parâmetro $\mathrm{DBO}$, a condição de lançamento admitida pela atual legislação exige remoção mínima de $60 \%$ para lançamento de efluentes. Como o presente estudo não teve o objetivo de mensurar a eficiência do tratamento empregado na estação de tratamento, não foi possível avaliar o atendimento à legislação nesse aspecto. Contudo, considerando-se a faixa mínima estimada de DBO para efluentes brutos de abatedouros, que é de $800 \mathrm{mg} / \mathrm{L}$ (Braile; Cavalcanti, 1993), verifica-se que a ETE aqui estudada atendeu à legislação apenas nos meses de setembro e janeiro. O parâmetro DBO retrata, de uma forma indireta, o teor de matéria orgânica nos esgotos ou no corpo d'água, sendo, portanto, uma indicação do potencial do consumo de oxigênio dissolvido. A presença de um alto teor de matéria orgânica pode induzir ao completo esgotamento do oxigênio na água, provocando $\mathrm{o}$ desaparecimento de peixes $\mathrm{e}$ outras formas de vida aquática (Azzolini et al. 2011).

Para o parâmetro demanda química de oxigênio (DQO), cujas variações ocorreram de maneira gradativa, não existem valores máximos estabelecidos pela legislação, podendo-se adotar, para fins de comparação, algumas legislações estaduais. No caso de Minas Gerais, o valor máximo de DQO a ser lançado no efluente é de $180 \mathrm{mg} / \mathrm{L}$, sendo as concentrações obtidas no efluente do abatedouro aqui pesquisado superiores a este parâmetro em todos os meses de monitoramento. Já no estado do Rio Grande do Sul a concentração máxima de DQO é de $400 \mathrm{mg} / \mathrm{L}$. Considerando este limite, o efluente aqui pesquisado estaria em acordo apenas no mês de setembro. Pode-se então admitir, com base nessas comparações, que os valores para a DQO aqui encontrados foram elevados.

Tanto a DQO quanto a DBO mostraramse elevadas no monitoramento realizado, revelando-se indicadores preocupantes já que os efluentes são despejados em corpo hídrico logo abaixo da última lagoa. Outro aspecto evidenciado foi o forte odor no entorno da ETE do abatedouro, que apesar de estar localizada na região do Distrito Industrial (fora da zona urbana), tem afetado sobremaneira quem convive nas proximidades.

Quanto aos resultados das análises microbiológicas, uma vez que não existem valores máximos de coliformes termotolerantes ou E. coli recomendados pela legislação federal, ao se traçar um comparativo com os limites de legislações estaduais, como a do Rio Grande do Sul, que estipula a concentração de 105 NMP/100 mL para coliformes termotolerantes e E. coli, verifica-se que as contagens de microorganismos aqui verificadas foram bem inferiores. Resultados semelhantes foram encontrados por Silva et al. (2012) quanto aos coliformes termotolerantes, cujo número variou de 460 a $2400 \mathrm{NMP} / 100 \mathrm{~mL}$ em uma ETE de 
abatedouro industrial de bovinos no Paraná e quanto à $E$. coli, que foi encontrada em todas as amostras de efluente analisadas pelos autores. Todavia, resultados bem inferiores foram obtidos por Fabbi et al. (2007) quanto aos Coliformes Termotolerantes em uma ETE de abatedouro industrial de suínos em Santa Catarina.

A natureza fecal e o conteúdo orgânico destes resíduos é fator que pode contribuir para acelerar 0 crescimento dos micro-organismos presentes nesse tipo de ETE, gerando ambiente propício aos coliformes e aumentando os picos do Número Mais Provável por mililitros nas amostras. As amplas flutuações identificadas em vários parâmetros analisados, como Coliformes Termotolerantes, E. coli, sólidos em suspensão totais, materiais sedimentáveis, DBO, DQO e nitrogênio amoniacal total evidenciaram a instabilidade do sistema de tratamento em manter um padrão nas concentrações de poluentes, que associadas ao forte odor percebido, evidenciam problemas operacionais na ETE.

Verificou-se ainda que não há um acompanhamento contínuo da estação, principalmente pelo fato da mesma não estar inserida na planta industrial do abatedouro. Os responsáveis pela operacionalização da estação possuem baixa capacitação profissional, inexistem medidores de vazão, controle do tempo de detenção das lagoas e monitoramento contínuo do efluente. Ressalta-se que, conforme a licença ambiental da empresa, o monitoramento deve ser feito mensalmente, porém, esta condicionante não é cumprida, pois as análises do efluente são realizadas apenas trimestralmente. Vale mencionar que o abatedouro em questão já sofreu punições por não cumprimento de exigências ambientais e sanitárias. Os resultados do presente estudo foram encaminhados ao Médico Veterinário, único responsável técnico do empreendimento, para adoção de medidas corretivas.

A caracterização do efluente tratado evidenciou seu alto potencial poluidor, não atendendo, portanto, aos padrões exigidos pela legislação federal vigente, não sendo, assim, recomendado para o reuso.

Recomenda-se que sejam adotadas algumas medidas preventivas no próprio processo produtivo, no sentido de minimizar a geração de efluentes, como a realização da coleta do máximo possível de sangue na sangria, aguardando o tempo necessário para a completa eliminação; e instalação de peneiras mais finas na entrada dos dutos que canalizam os efluentes, evitando o carreamento de sólidos com maiores diâmetros. Como medidas corretivas, sugere-se a inserção de medidores de vazão na ETE, instalação de dispositivos ou produtos para minimização de odores, capacitação dos profissionais envolvidos no manejo da estação e maior controle operacional da ETE, com fixação de cronogramas e prazos para realização das atividades operacionais (monitoramento do tempo de detenção das lagoas e retirada manual de sólidos suspensos). Sugere-se ainda que seja verificada a possibilidade de construção de uma lagoa de polimento (maturação) no final do processo, no sentido de inserir um tratamento aeróbio complementar, melhorando assim a qualidade microbiológica do efluente.

\section{CONCLUSÕES}

A qualidade dos efluentes gerados no abatedouro de bovinos avaliado pode ser considerada insatisfatória, uma vez que houve descumprimento da legislação vigente em relação a vários parâmetros analisados no presente monitoramento. Nesse sentido, o reuso do efluente tratado não é aconselhado, bem como o efluente não possui qualidade compatível com sua forma de descarte.

Este estudo representou uma contribuição ao setor de abatedouros, em especial da cidade de São Luís, MA. Em visitas a outros estabelecimentos, situações e falhas semelhantes do sistema produtivo, bem como ausências de controle operacional, de um adequado sistema de monitoramento da qualidade do efluente tratado e de medidas preventivas, também foram observadas. Isso vem evidenciar uma falha no sistema de fiscalização do Estado e a ausência de políticas públicas, em especial de legislações ambientais estaduais pertinentes a esse ramo agroindustrial.

\section{REFERÊNCIAS}

1. APHA. AWWA. WPCF. Standard Methods for the examination of water and wastewater.21. ed. Washington, 2005.

2. AZZOLINI, J. C.; FRINHANI, E. M. D.; FABRO, L. F. Águas industriais: controle 
físico-químico e biológico do efluente e medida da eficiência do tratamento na agroindústria. Unoesc \& Ciência - ACET, Joaçaba, v. 2, n. 1, p. 7-18, jan./jun. 2011.

3. BARROS, L. S. S. Estudo do potencial do impacto ambiental de águas residuárias de abatedouros avícolas e suinícolas. 2005. 147 f. Tese (Doutorado em Medicina Veterinária) Faculdade de Ciências Agrárias e Veterinárias, Universidade Estadual Paulista Júlio de Mesquita Filho. São Paulo, 2005.

4. BRAILE, P. M.; CAVALCANTI, J. E. W. A. Manual de tratamento de águas residuárias industriais. São Paulo: CETESB, 1993. 764 p.

5. BRASIL. CONSELHO NACIONAL DO MEIO AMBIENTE - CONAMA. Resolução $n^{\circ} 430$, de 13 de maio de 2011. Dispõe sobre as condições e padrões de lançamento de efluentes, complementa e altera a Resolução $\mathrm{n}^{\circ}$ 357, de 17 de março de 2005, do Conselho Nacional do Meio AmbienteCONAMA. Disponível em: <http://www.mma.gov.br/port/conama>. Acesso em 16 jan. 2011.

6. CAIXETA, C. E. T.; CAMMAROTA, M. C.; XAVIER, A. M. F. Slaughterhouse wastewater treatment: evaluation of a new three-phase separation system in a UASB recator. Bioresource Technology, v. 81, n. 1, p. 61-69, 2002.

7. CORDI, L.; ASSALIN, M. R.; DIEZ, M. C.; DURAN, N. Montagem, partida e operação de um sistema de lodos ativados para o tratamento de efluentes: parâmetro físicoquímicos e biológicos. Revista Engenharia Ambiental, Espírito Santo do Pinhal, v.5, n.1, p.97-115, 2008.

8. CREPALLI, M. S. Qualidade da água do Rio Cascavel. 2007. 77 f. Dissertação (Mestrado em Engenharia Agrícola) - Centro de Ciências Exatas e Tecnológicas, Universidade Estadual do Oeste do Paraná, Paraná, 2007.

9. DEL POZO, R.; DIEZ, V.; BELTRÁN, S. Anaerobic pre-treatment of slaughterhouse wastewater using fixed-film reactors. Bioresource Technology, v. 71, n. 2, p. 143149, 2000.

10. DIAS, M. C. O.; PEREIRA, M. C. B.; DIAS, P. L. F. Manual de Impactos Ambientais: orientações básicas sobre aspectos ambientais de atividades produtivas. Fortaleza: Banco do Nordeste, 1999. 297 p.

11. DORNELLES. F. Análise da gestão dos tratamentos dos efluentes gerados nos abatedouros de bovinos de São Luiz Gonzaga. 2009. 103 f. Dissertação (Mestrado em Engenharia de Produção) - Centro de Tecnologia, Universidade Federal de Santa Maria, Santa Maria, 2009.

12. FABBI, L. M.; FRANÇA, R. G.; TOMAZELLI, I. B.;FILIPINI, T. A. Monitoramento de efluentes em agroindústrias de Chapecó, Santa Catarina. Revista de Ciências Ambientais, v. 1, n. 2, p. 67-82, 2007.

13. FERREIRA, I. V. L; WIECHETECK, G.; DELUQUI, K. K.; ADRIANI, M. S. Impactos ambientais de abatedouros e medidas mitigadoras. In: CONGRESSO INTERAMERICANO DE ENGENHARIA SANITÁRIA E AMBIENTAL, 28., 2002, Cancun. Anais... Cancun: AIESA, 2002. CDROM.

14. FIGUEIREDO, M. C. B.; TEIXEIRA, A. S.; ARAÚJO, L. F. P.; ROSA, M. F.;PAULINO, W. D.; MOTA, S.; ARAÚJO, J. C. Avaliação da vulnerabilidade ambiental de reservatório ambiental. Engenharia Sanitária e Ambiental, v. 12 , n. 4, p. 399-409,2007.

15. GIL, A. S. L. Caracterização do efluente de ETE de abatedouro visando o reuso. 2010. 77 f. Monografia (Graduação em Engenharia Ambiental) - Faculdade de Engenharia e Arquitetura, Universidade de Passo Fundo, Passo Fundo, 2010.

16. GIORDANO, Gandhi. Tratamento e controle de efluentes industriais. 2004. 81 p. Apostila (Efluentes Industriais). Departamento de Engenharia Sanitária e do Meio Ambiente UERJ.

17. GLEBER, L. Redução de riscos de impacto ambiental na produção integrada das maçãs. Circular técnica, n. 38, julho/2002.

18. GOMES, B. M. F. Pré-Tratamento FísicoQuímico de Efluentes Industriais de um Abatedouro de Bovinos. 2010. $77 \mathrm{f}$. Monografia (Graduação em Engenharia Ambiental) - Universidade de Passo Fundo, Passo Fundo, 2010.

19. HENZEL, M. H.; SILVEIRA, D. D. Análise de resíduos como mecanismo de auxílio à

20. redução de impactos ambientais: um estudo de caso em abatedouro. Iberoamerican Journal of Industrial Engineering, v.1, n. 2, p. 76-100, 2009.

21. IBGE - Instituto Brasileiro de Geografia e Estatística. Anuário Agropecuário - Brasil 2014. Rio de Janeiro: IBGE, 2014. 
22. JOHNS, M. R. Developments in wastewater treatment in the meat processing industry: a review. Bioresource technology, v. 54, n. 3, p. 203-216, 1995.

23. LIBÂNIO, M. Fundamentos de Qualidade e Tratamento de Água. Campinas/SP: Editora Átomo, 2005. 444 p.

24. MACIEL JR., P. Zoneamento das águas: um instrumento de gestão dos recursos hídricos. 1. ed. Belo Horizonte: IGAM, 2000.112 p.

25. MANIOS, T.; GAKI, E.; BANOU, S.; KLIMATHIANOU, A.; ABRAMAKIS, N.; SAKKAS, N. Closed wastewater cycle in a meat producing and processing industry. Resources, Conservation and Recycling, v. 38, n. 4, p. 335-345, 2003.

26. MORAES, L. M.; PAULA JÚNIOR, D. R. Avaliação da biodegradabilidade anaeróbia de resíduos da bovinocultura e da suinocultura. Engenharia Agrícola, v. 24, n. 2, p. 445-454, 2004.

27. MASSÉ, D. I.; MASSE, L. The effect of temperature on slaughterhouse wastewater treatment in anaerobic sequencing batch reactors. Bioresource Technology, v. 76, n.2, p. 91-98, 2001.

28. NAIME, R.; GARCIA, A. C. Utilização de enraizadas no tratamento de efluentes agroindustriais. Estudos Tecnológicos, v.1, p.9-20, 2005.

29. NIETO, R. Caracterização ecotoxicológica de efluentes líquidos industriais: ferramenta para ações de controle da poluição das águas. In: CONGRESSO INTERAMERICANO DE ENGENHARIA SANITÁRIA E AMBIENTAL, 27., 2000, Porto Alegre. Anais eletrônicos... Porto Alegre: ABES, 2000. Disponível em: $<$ http://www.abes-dn.org.br.htm >. Acesso em: 2 ago. 2013.

30. PIVELLI, R. P. Tratamento de esgotos sanitários. Maceió: Centro de Tecnologia, $2012 . \quad$ Disponível em: $<$ http://www.ctec.ufal.br>. Acesso em: $26 \mathrm{fev}$ 2015.

31. SALMINEN, E. A.; RINTALA, J. A. semicontinuous anaerobic digestion of solid poultry slaughterhouse waste: effect of hydraulic retention time and loading. Water Research, v. 36, n. 13, p. 3175-3182, 2002.

32. SANTOS, H. R. Coagulação/precipitação de efluentes de reator anaeróbio de leito expandido e de sistema de lodo ativado precedido de reator UASB, com remoção de partículas por sedimentação ou flotação. 2006. 331 f. Tese (Doutorado em Hidráulica e Saneamento) - Escola de Engenharia de São Carlos, Universidade de São Paulo, São Carlos, 2006.

33. SILVA, S. V.; PEREIRA, R. A.; PIVELI, R. P.; CRISCUOLO, H. J. Monitoramento das

34. características dos esgotos como instrumento de otimização do processo de lodos ativados e suas implicações. Revista Brasileira de Ciências Ambientais, n. 2, p. 46-59, 2005.

35. SILVA, E. L.; CORTEZ, D. A. G.; GONÇALVES, J. E. Estudo físico-químico e microbiológico do potencial impactante do efluente de abatedouros avícola e bovino. In: MOSTRA INTERNA DE TRABALHOS DE INICIAÇÃO CIENTÍFICA, 6., 2012, Maringá. Anais Eletrônico. Maringá: CESUMAR, 2012

36. SOUSA, J. T.; CEBALLOS, B. S. O.; HENRIQUE, I. N.; DANTAS, P. D.; LIMA, S. M. S. Reúso de água residuária na produção de pimentão (Capsicum annuum L.). Revista Brasileira de Engenharia Agrícola e Ambiental, v.10, p.89-96, 2006.

37. TORKIAN, A.; EQBALI, A.; HASHEMIAN, S. $J$. The effect of organic loading rate on the performance of UASB reactor treating slaughterhouse effluent. Resources, Conservation and Recycling, v. 40, n. 1, p. 111, 2003.

38. VON SPERLING, M. Princípios básicos de tratamento de esgotos: princípios do tratamento biológico de águas residuárias. Belo Horizonte: Departamento de Engenharia Sanitária e Ambiental da Universidade Federal de Minas Gerais, 1996. 